\title{
Prospects of the Social Agricultural Robot Creation
}

\author{
Anna Aletdinova, Maxim Kravchenko, Yana Tsybina \\ Automated Control Systems department \\ Novosibirsk State Technical University \\ Novosibirsk, Russian Federation \\ aletdinova@corp.nstu.ru; lint_5@mail.ru; janatsybina@yandex.ru
}

\begin{abstract}
Attempts of the society to facilitate human work and life led to the creation of robots. Unfortunately, there are no existing social agricultural robots yet. If we combine the functions of agricultural robots used on a private plot of land or a vegetable garden and the functions of social robots realized in interaction with humans into a social agricultural robot, we can get some kind of hybrid, i.e. robot-companion and assistant, used for personal purposes. This robot is another unofficial member of the rural household. Authors believe that a social agricultural robot is a technical tool, a machine capable of social interaction with a person and performing horticultural, livestock, meliorative, and service types of work. It will be able to implement the function of performing agricultural operations and a communicative one. To create it, a high level of technology development will be required: computer vision, understanding of speech, sensory networks, bionic systems, navigation systems, power supplies. A sociological survey conducted showed that Russian rural population see social agricultural robots as helpers on a plot of land, in the garden and in the house. The result obtained is interesting because it allows us to talk about further modifications of social agricultural robots. At present, the creation of such robots would make work and life of the rural population easier and safer and solve some problems of preserving the ecology. Social agricultural robots could work with pesticides which are harmful to human health; implement technologies of point agriculture and resource saving; provide employment for people with disabilities in agricultural activities; increase the mobility of the rural population through the use of remote management; participate in the organization of leisure and self-education of people.
\end{abstract}

Keywords-agricultural robots; social robots; robot technology; robot capabilities; rural population

\section{INTRODUCTION}

Physical labor on the land has always been considered as arduous. Perhaps that is why in the 20 century there was such a massive migration of the population to cities, to more developed infrastructure, to enterprises with a predominance of automated and intellectual labor. The number of agricultural producers has sharply decreased. The number of people engaged in housekeeping in the countryside continues to decrease, in particular, those who are engaged in the maintenance of livestock and birds, the cultivation of berries and vegetables on household plots (See Table I). At the same time, scientists are sounding the alarm about the growing problems of sustainable development and hunger on the planet. The agricultural sector lags behind other industries in the application of the following technologies: bio- and nanotechnology, genetic engineering, membrane and quantum technologies, micromechanics, robotics.

TABLE I. NUMBER OF PERSONS ENGAGED IN RURAL LABOR TO PRODUCE GOODS FOR OWN USE IN RUSSIA, THOUSAND PEOPLE [1]

\begin{tabular}{|l|l|l|}
\hline \multirow{2}{*}{ Groups } & \multicolumn{2}{c|}{ Period } \\
\cline { 2 - 3 } & \multicolumn{1}{|c|}{$\begin{array}{c}\text { The second quarter of } \\
\text { 2016 }\end{array}$} & $\begin{array}{c}\text { The second quarter of } \\
\mathbf{2 0 1 7}\end{array}$ \\
\hline Total & 10617 & 9683 \\
\hline Men & 4975 & 4495 \\
\hline Women & 5641 & 5188 \\
\hline
\end{tabular}

This is due to the shortage of production resources associated with the reproduction of obsolete elements of the third and fourth technological structures. The agro-industrial complex requires serious technical and technological renovation.

Analysis of the publication activity of scientists has shown interest in the research of agricultural and social robots around the world (See Table II).

TABLE II. THE NUMBER OF PUBLISHED SCIENTIFIC PAPERS DISCOVERED USING GOOGLE SCHOLAR (2011-2017)

\begin{tabular}{|l|c|c|c|c|}
\hline \multicolumn{1}{|c|}{ Search queries } & \multicolumn{4}{|c|}{ Period } \\
\cline { 2 - 5 } & $\begin{array}{c}\mathbf{2 0 1 1 -} \\
\mathbf{2 0 1 2}\end{array}$ & $\begin{array}{c}\mathbf{2 0 1 3 -} \\
\mathbf{2 0 1 4}\end{array}$ & $\begin{array}{c}\mathbf{2 0 1 5 -} \\
\mathbf{2 0 1 6}\end{array}$ & $\begin{array}{c}\text { Tilt } \\
\text { september } \\
\mathbf{2 0 1 7}\end{array}$ \\
\hline Agricultural robots & 16251 & 20549 & 25455 & 3871 \\
\hline Social robots & 82400 & 86400 & 88900 & 18530 \\
\hline
\end{tabular}

The number of articles and books devoted to the development, application and improvement of such robots is growing every year. This emphasizes the relevance of the chosen research topic.

The share of the rural Russian population is $26 \%$ of the total population of the country for eight years already. His strength declines, but insignificantly. At the same time, compared to the 1980 s, there were fewer schools, hospitals, libraries, etc. in the countryside. Social infrastructure, if there is, is located far enough from many settlements due to large areas of rural areas and low population density. In this situation, new breakthrough technologies, in particular, the development of robotics, can help the rural population. It is urgent to investigate the need for social agricultural robots in households, their possible features and functions.

\section{FEATURES OF AGRICULTURAL ROBOTS}

Let's look at the concept of an agricultural robot. Z. Libin, Y. Qinghua, B. Guanjun, W. Yan, Q. Liyong, G. Feng, X. Fang, give the following definition: it is programmable 
automated or semi-automatic equipment for obtaining agricultural products, that have functions of human perception and action [2]. A technical tool, a machine capable of efficiently performing work based on various software algorithms [3]. Its specific feature was the need to focus on the changing agrolandscape and exposure to weather. Agricultural robots can be divided into areas of activity for horticultural, livestock and reclamation. In addition, according to the technical design, they divide two main subsystems: an autonomous vehicle and an autonomous implement. An autonomous vehicle, for example, an automated conventional tractor, which is itself sent to the field to perform a given operation, such as sowing harvesting, weed control. At the same time, the operation itself is performed by an autonomous implement mounted on the vehicle. The implementation of such a complex task requires a large number of specialized sensors and actuators, which should function as a single system.

As noted by H. Hagras, M. Colley, V. Callaghan, M. CarrWest, they should be able to adapt to any changes in the kinematics of the environment in a short period of time without repeating the training cycle from the very beginning [4]. At the same time, the functioning of robotic systems must be reliable, with high resistance to failures and a low level of negative environmental impact.

The specifics of work in rural areas impose their own requirements on the creation of agricultural robots. Let us single out these requirements: dependence on weather and climate conditions; carrying out operations with soil and plants, with animals and pests; on uneven surfaces and soil with different conditions, in confined spaces. The operations must be carried out in such a way as to optimize the movement time of the robots.

World practice shows that the creation and application of robots in agriculture is a real task. In Japan, according to some estimates, about 10.000 units of such equipment are already involved in this direction. As an example, this is a compact robot gardener from the company Toshiba, which was designed for planting trees, pruning their branches and other similar work [5].

In Europe, agricultural milking robots are the most common. The main producers of robots for agriculture are DeLaval (Sweden), Fullwood (Great Britain), Insentec (Holland), Lely (Holland), GEA Farm Technologies (Germany). According to researchers of the robotics market, as of 2011, agricultural robotics accounted for $39 \%$ of the total robot market in Europe [6]. Similarly in Russia, the most common are robots for livestock [7].

In the US, as part of a set of measures to revive American industry, the National Robotics Initiative (NRI) exists. This program is dedicated to allocating funds and determining the conditions for financing research in the field of agricultural robotics. One of the key principles of this program is the attraction of the most powerful universities through the system of grants. This approach has already allowed in the US to form profile clusters. Among the most significant of these are the Silicon Valley Cluster, the Pittsburgh Cluster, the Massachusetts Cluster. According to MassTLC for the period from 2005-2011. more than \$ 200 million has been invested in robotic projects. The growth of income of companies specializing in robotics for agriculture, in the period 20082011 was $6.1 \%$ [8].

In publications, the term "rural smart economy" already exists, it is a high-tech cluster that introduces innovative technologies, in particular, the smart generation of agricultural machinery [9-11] According to the European agricultural machinery market, $70 \%$ of machines for performing fertilization and spraying operations, already operate on the basis of smart technologies [12].

An ambitious American project is used for mass use on small household plots. The robot Tertill from Franklin Robotics is designed for around the clock work in the garden or garden [13]. Outwardly it looks like a robotic vacuum cleaner. Tertill is able to weed the beds and carry out their watering if necessary.

In Russia, despite the weak development of robotics, there are a number of projects in agriculture. Technological Institute of the JURI has developed a prototype of the self-propelled agricultural robot-cultivator. Field trials are scheduled for autumn 2017 [14]. The All-Russian Institute of Mechanization also deals with the development of robotic devices for agriculture in Russia.

Thus, robots are already an integral part in the agricultural sector of Russia and a number of countries. However, as you can see, many robots are engaged in solving narrow tasks, and is not focused on more complex communication with humans.

\section{FEATURES OF COSIAL ROBOTS}

A social robot is a robot that is capable of social interaction with a person and takes into account the social context $[15,16]$. C. Breazeal notes that social robots as a class people try to make anthropomorphic [17]. S. Woods, K. Dautenhahn, C. Kaouri, R. Boekhorst, K. L. Koay write that they should "participate in real human-robotic interactions" [18].

Similar to the concept of social robots - robots are service and personal, and although they have their definitions, in our opinion, social robots can be of these two types and used by citizens for non-commercial, personal purposes.

Such robots can help the household, people with disabilities, conduct cultural and entertainment events, act as training partners, teachers and simply interlocutors. C. Breazeal classifies robots according to their roles: instruments, continuation of the body, avatars or social partners [17]. N.N. Zilberman divides robots by functions: assistants, companions, media robots [15].

As an example of a robot assistant, the development of the Karlsruhe Institute of Technology and the Using the Template of Information Technologies FZI, ARMAR can be cited. This robot understands verbal commands and gestures, is able to navigate in space thanks to cameras and sensors. The developers have created ARMAR to help people in the kitchen, for example, a robot can easily get something from the refrigerator [19]. 
There is an interesting project of developers from the Massachusetts Institute of Technology (MIT) in the creation of the robot companion Jibo. He understands human speech, is able to recognize people's faces and determine their emotional state, which allows him to respond and conduct a dialogue in accordance with the mood of the owner. The robot, thanks to the connection to the Internet, can give advice on various issues, for example, to clarify the recipes of the dish or to report on emails received by e-mail. Using the robot, users can make audio and video calls. Jibo also knows how to tell fairy tales to children, or anecdotes to parents, which makes it possible to use this robot for the whole family [20].

An additional important function of social robots is the care of the elderly, as there is an increasing number of people in need of help and 24-hour attention due to aging of the population. Robots for the care of the elderly are already being used in hospitals, nursing homes. They can be exoskeletons. They can be worn by elderly people for their own movement, as well as medical assistants in moving older people. In 2013, Japan initiated a program to pay $2 / 3$ of the costs associated with developing inexpensive robots to care for the elderly and to improve the delivery of social security to older people at home. This again emphasizes the importance of creating robotics for the social sphere.

In addition, the spread of gaming creates new markets for robotics, where users are children and adults (including older people). Such development of robotics has a serious impact on children, as a new generation of users is formed, since childhood familiar with not only the operation, but also the creation of robots. For example, in the United States, specialized programs on robotics have been launched within the framework of state programs on the development of STEM competencies (Science, Technology, Engineering, and Mathematics). Thus, gaming penetrates both the usage processes and the creation of robots.

However, at present, the main problems of the spread of social robots are their high cost and inconsistency with consumers' expectations [21]. These problems also apply to agricultural robots. We predict that it will be solved by their subsequent modifications, the use of new inexpensive materials and serial large-scale production.

So, Intel company in 2015 presented its solution to the problem of high cost of robots. The social robot Jimmy, the main feature of which is that most of its components are printed on a 3D printer, and most importantly, all necessary 3D models for printing are freely available [22]. Home printing will significantly reduce the price of the robot, the other necessary components will be provided by Intel when ordering.

Thus, the considered features of social robots, show their significance when interacting with a person. Robots will be able to radically change the life of society, but so far require new developments and improvements in robot technology.

\section{THE POSSIBILITIES OFSOCIAL AGRICULTURAL ROBOTES}

Social agricultural robots do not yet exist, but with the development of society's needs and the further development of robotics, they must emerge. Prerequisites for their appearance should serve as technological drivers, providing development in technologies that are the basis of robotics. Considering the level of robot technology development, it should be noted that it is higher for the social field (See Table III).

The discrepancy in the development of technologies can be explained by the specifics and size of spheres of activity, a wide range of tasks.

TABLE III THE LEVEL OF ROBOT TECHNOLOGY DEVELOPMENT [23]

\begin{tabular}{|l|l|l|l|}
\hline \multirow{2}{*}{ Technologies } & \multicolumn{3}{|c|}{ Application area } \\
\cline { 2 - 4 } & $\begin{array}{c}\text { Work at } \\
\text { home }\end{array}$ & $\begin{array}{c}\text { Care for } \\
\text { people with } \\
\text { disabilities }\end{array}$ & Agriculture \\
\hline Computer vision & Average & Low & High \\
\hline $\begin{array}{l}\text { Speech } \\
\text { understanding }\end{array}$ & High & High & Low \\
\hline Sensor networks & High & High & Average \\
\hline Bionic system & Low & High & Low \\
\hline Navigation systems & Average & Average & High \\
\hline Power supplies & High & High & Low \\
\hline Microrobots & Low & Average & Low \\
\hline
\end{tabular}

The authors outlined the main features of agricultural and social robots on the basis of the characteristics of their perception of society, the main functions, scope, types, specific features and necessary technologies for their creation (See Table IV). This allowed us to go on to describe the social agricultural robots.

TABLE IV CHARACTERISTICS OF AGRICULTURAL AND SOCIAL ROBOTS

\begin{tabular}{|c|c|c|}
\hline \multirow[t]{2}{*}{ Characteristics } & \multicolumn{2}{|c|}{ Robots } \\
\hline & Agricultural & Social \\
\hline Society Perception & Mechanism & Social Partner \\
\hline Primary Function & $\begin{array}{l}\text { Carrying out of } \\
\text { agricultural operations }\end{array}$ & Communicative \\
\hline Application area & Agricultural & $\begin{array}{l}\text { Working from home } \\
\text { Care for disabled } \\
\text { people } \\
\text { Leisure and games }\end{array}$ \\
\hline Kinds & $\begin{array}{l}\text { Garden field } \\
\text { Livestock } \\
\text { Meliorative } \\
\end{array}$ & $\begin{array}{l}\text { Personal } \\
\text { Service }\end{array}$ \\
\hline Specific features & $\begin{array}{l}\text { Orientation in the } \\
\text { agricultural landscape } \\
\text { Weather resistance }\end{array}$ & Interaction with man \\
\hline $\begin{array}{l}\text { Basic necessary } \\
\text { technologies of } \\
\text { robot construction }\end{array}$ & $\begin{array}{l}\text { Computer vision } \\
\text { Sensory networks } \\
\text { Bionic networks } \\
\text { Navigation system } \\
\text { Power Supplies }\end{array}$ & $\begin{array}{l}\text { Computer vision } \\
\text { Sensory networks } \\
\text { Bionic networks } \\
\text { Navigation system } \\
\text { Power Supplies } \\
\text { Understanding } \\
\text { Speech }\end{array}$ \\
\hline
\end{tabular}

We think that such a robot will be perceived by society as a social partner, i.e. assistant around the house and on the plot, a nice conversationalist. Understanding speech will be one of the main necessary technologies when creating it. A social agricultural robot will facilitate everyday life in the countryside, performing two basic functions - conducting agricultural operations and communicative. Such a robot can be a horticultural, livestock and service. The least demand will be used by social reclamation robots. The necessary 
technologies to ensure its creation will be computer vision, sensory networks, bionic networks, a navigation system, understanding of speech and power sources. The condition of his humanlike nature remains controversial. This will probably be related to the problem of how androids can perform well the functions of agricultural robots.

A sociological poll on the possibility of using social agricultural robots by the Russian population gave the following results (See Figure 1).

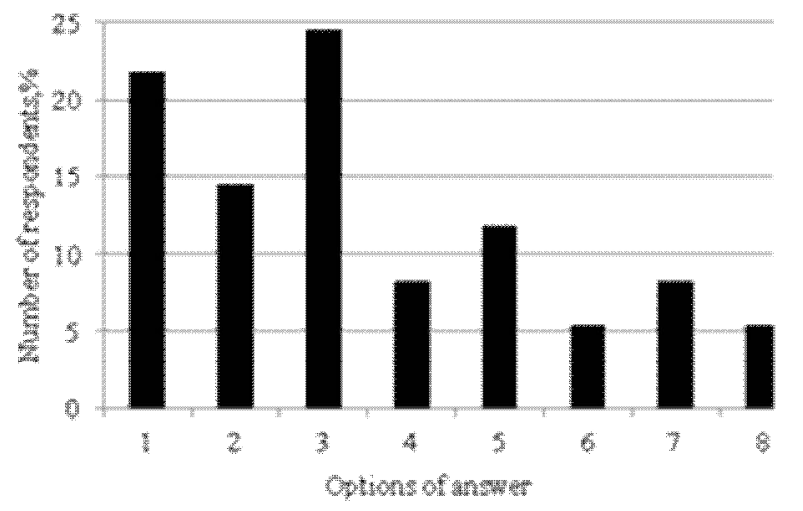

Fig. 1. Distribution of respondents' answers to the question: "What for you will use social agricultural robots?"

All respondents confirmed the need for such robots. Options of answers "for what purpose" are chosen the following:

1) Help in the garden / on the plot of land.

2) Breeding of domestic animals.

3) Help with cleaning in the house, cooking.

4) Looking after children in the house and on the street.

5) Cleaning of the land near the house.

6) Care of elderly people, disabled people and other persons with limited ability to work, assistance in rehabilitation and communication with them.

7) Broadcast music in and around the house.

8) Household repair, construction on the land.

The most popular goals were: help in the garden, help with cleaning in the house, cooking. The following assignments were allocated: agricultural, logistical, cultural-entertaining, rehabilitation and educational, homework.

Thus, respondents add new functions to social agricultural robots. They in the rural household need an assistant not only on the plot, but also in the house. It can be assumed that after the emergence of social agricultural robots, the creation of their various modifications, humanity will come to the construction of a universal for the household robot-helper, which, among other things, performs agricultural operations.

\section{CONCLUSIONS}

In our opinion, it is required to create and distribute social agricultural robots that will be able to combine the functions of agricultural and social robots, facilitating the work and life of a person. Necessary technologies of computer vision, understanding of speech, sensory networks, bionic systems, navigation systems, power sources have already been created, although they require improvement. The authors believe that social agricultural robots will be able to:

- solve the problem of harmful effects on human health from pesticides with manual spraying and reduction of environmental pollution;

- perform physical work and various assignments of the owners;

- ensure the participation of disabled people, pensioners, women on maternity leave, etc. in the management of agricultural work, i.e. category of the population that can't fully engage in economic activities in its physical state under current conditions;

- increase the mobility of the rural population through the remote management of their household plots;

- to engage in leisure of citizens;

- help them in self-learning;

- brighten up loneliness, cheer up, etc.

Their field of application will be limited to the territory of a private land or a garden with close interaction with human from long and short distances. The results of the sociological survey show the interest of the population in the use of social agricultural robots.

Thus, the robotization of technical processes will lead to decrease in the share of manual labour and the incease in the intellectual one, mitigate harmful impact on human and the environment; attract a part of unemployed population into agriculture. Attraction of these robots to village life will enable them to partially realize the function of the social service to facilitate their life and to improve the quality of life consequently.

\section{REFERENCES}

[1] GKS. (2017). Retrieved from: http://www.gks.ru/

[2] Z. Libin, Y. Qinghua, B. Guanjun, W. Yan, Q. Liyong, G. Feng, X. Fang, "Overview of research on agricultural robot in China," International Journal of Agricultural and Biological Engineering, vol. 1, No. 1, pp. 12-21, August 2008.

[3] W. H. P. Guimarães, M. V. M. Ferreira, J. Tavares, "Automated Planning Applied In Robot Trajectory Control System," IFAC Proceedings Volumes, vol. 46, No. 24, pp. 171-176, December 2013.

[4] H. Hagras, M. Colley, V. Callaghan, M. Carr-West, "Online learning and adaptation of autonomous mobile robots for sustainable agriculture," Journal of Autonomous Robots, vol. 13. No. 1, 2002, pp. 37-52.

[5] S.V. Shanygin, "Robots as Means of Agriculture Mechanization,"Proceedings of Higher Educational Institutions. Machine Building, No. 3, 2013, pp. $39-42$.

[6] Industrial and service robotics in Europe (2011). Retrieved from: https://www.slideshare.net/bizresonance/robotique-industrielle-et-deservice-europe-aout-2011-8839337

[7] B.D. Dokin, A.A. Aletdinova, M.S. Kravchenko, "Prospects and features of robotics in russian crop farming," Journal of Physics: Conference Series, vol. 803, 2017, iss. 1, art. 012032 (7 p.).

[8] E.A. Skvortsov, E.G. Skvortsova, "Trends of Development of Agrocultural Robotics Abroad," Agrarian Bulletin of the Urals, No. 1, 2016, pp. $37-43$.

[9] Z.E. Armağan., "Global trends in agriculture and technological solutions," Fifth World Summit on Agriculture Machinery: 2016, p.28.

[10] A. Mehta, S. Patel, "IOT based smart agriculture research opportunities," International Journal For Technological Research In Engineering, vol. 4, iss. 3, November 2016. 
[11] M. Taylor. (2017). Climate-smart agriculture: what is it good for? The Journal of Peasant Studies. https://doi.org/10.1080/0306615 0.2017 .1312355

[12] Enabling Smart Farming in Europe. (2015). Retrieved from: $\mathrm{http}$ //www.cema-agri.org/page/enabling-smart-farming-europe- 0

[13] Franklinrobotics. (2017).

Retrieved

from: http://www.franklinrobotics.com

[14] Expert building portal. (2017). In the Kuzbass have developed an agro robot. Retrieved from: http://estp-blog.ru/news/nid-28525/

[15] N.N. Zilberman, "Functional Classification of Social Robots," Humanitarian Informatics, No. 8, 2014, pp. 30 - 39.

[16] C. Bartneck, J. Forlizzi, "A design-centred framework for social humanrobot interaction," Robot and Human Interactive Communication: 13th IEEE International Workshop on 2004: pp. 591-594.

[17] C. Breazeal, "Social interactions in HRI: the robot view," IEEE Transactions on Systems, Man, and Cybernetics, Part C (Applications and Reviews), vol. 34, No. 2, 2004, pp. 181-186.

[18] S. Woods, K. Dautenhahn, C. Kaouri, R. Boekhorst, K. Koay, "Is this robot like me? Links between human and robot personality traits," Humanoid Robots 2005: 5th IEEE-RAS International Conference on. IEEE: 2005, pp. 375-380.
[19] M. Prats, S. Wieland, T. Asfour, A P.del Pobil, R. Dillmann, "Compliant interaction in household environments by the ArmarIII humanoid robot," Humanoid Robots 2008: 8th IEEE-RAS International Conference on. IEEE 2008: pp. 475-480.

[20] Jibo Robot. (2017). Your definition of robot is about to change. Retrieved from: https://www.jibo.com/

[21] C. Wood. (2017). Barriers to Innovation Diffusion for Social Robotics Start-ups: And Methods of Crossing the Chasm, p. 38. http://www.divaportal.org/smash/record.jsf?pid=diva2\%3A1109 $835 \&$ dswid $=-7238$

[22] About Jimmy the Robot. (2017). Retrieved from: http://www.21stcenturyrobot.com/about-jimmy

[23] RBC. (2016). Retrieved from: http://www.rbc.ru/ 